\title{
Crude Oil Futures Hedging Strategies During COVID- 19 Using VaR-Garch Models
}

\author{
Qitong Wang* \\ School of Business, University of Jinan, Jinan, Shandong 250000, China \\ *Corresponding author. Email: kiara.wqt@gmail.com
}

\begin{abstract}
In 2020, under the sweeping impact of the COVID-19 pandemic and a series of chain reactions that followed, the crude oil industry was hit hard. The most influential event was the price collapse of WTI futures and the unprecedented huge loss of some investors holding crude oil related products in their personal account in Bank of China. How to avoid the risk of fluctuations in prices for crude oil futures when encompassing extreme event? US WTI spot price and the futures price were analyzed to obtain the optimal hedging strategy for futures. First, crude oil futures and spot closing price were set as benchmarks, the following tests are carried out on their returns respectively: Auto-correlation test, Descriptive statistical test, Stability test, Co-integration test and Granger causality test; next, historical simulation and delta-normal method were applied to calculate the return rate of crude oil spot and hedged combination respectively, and it was proved that the hedging has a good effect.
\end{abstract}

Keywords: Crude Oil Futures, GARCH Model, VaR Model, Optimal Hedging Ratio

\section{INTRODUCTION}

\subsection{Research Purpose}

Crude oil is a global industry which sheds profound influences in global economy, no one can survive the catastrophic hit to the crude oil industry. For example, the price of the WTI Contract's May 2020 expiration crashed on April 20, 2020, Eastern Time, which was settled at negative crude oil price of USD $-37.63 /$ barrell, and the investors were directly affected by the unexpected Black Swan[1]. How can corporate and individual investors leverage risk management to hedge the potential investment risk and increase both the robustness of investment account and returns in volatile markets, and minimize losses in black swan events, this will be an important proposition. Specifically, the practical significance of this paper are as follows: (1) This paper examined risk-minimizing hedged strategy with futures contracts and provided approaches on risk management for investors to respond to the economic downturn. (2) VaR was applied to measure the risk level of the asset portfolio and the GARCH model was leveraged to estimate the optimal hedging ratio for the crude oil futures. Furthermore, the hedging effectiveness was tested to realize the quantitative design of the trading strategy. (3) The model was applied to the real WTI crude oil price and the real-time price (both spot prices and futures prices) to verify the empirical effect of the quantitative model and improve the credibility of the analysis results.

\subsection{Literature Review}

At the beginning, Keynes and Hicks optimized the normal Backwardation Theory from an economic perspective[2]. They believed that the purpose of hedgers' participation in futures trading is not to obtain high profits from futures trading, but to use profits of futures trading to make up for possible losses in the spot market. If the price fluctuations in the futures market and the spot market were the same, and suppose there were no transaction costs and taxes, perfect hedging can be achieved. However, Working, $\mathrm{H}$ further demonstrated that hedging is not only for avoiding risks, but also for maximizing returns. They chose the transaction to avoid the big risk instead of investing in small basis risk[4]. Afterwards, Johnson suggested that hedging is essentially a process of oil spot/futures portfolio, and hedgers optimize the portfolio according to risk preference and expectations, with the goal of obtaining maximum profit under the minimum risk. Ederington proposed that the minimum variance hedge ratio can be defined as the ratio of the covariance of the futures price series and the spot 
price series to the variance of the futures price series and pointed out that the slope coefficient obtained using the OLS method is the minimum variance hedge ratio[5]. Herbst, Myers and Caples believed that the use of OLS would cause residual auto-correlation problems, and based on this, to improve the model accuracy, they proposed to use a ARIMA method to estimate the minimum risk hedge[6]. Moreover, Myers and Baillie used the GARCH model to study the optimal hedging ratio of soybean and corn contracts and found that the hedging effect was significantly improved compared to the static model. They also proposed B-GARCH model which has made up a defect on covariance sequence that GARCH model cannot reflect[7].

Peng Hongfeng compared the hedging performance of the binary GARCH model and the OLS model and found that the BGARCH model and the OLS model are both effective in hedging the risk of spot price fluctuations, but the B-GARCH model is more effective[8].

Since J.P. Morgan's and Reuters' release of their volatility and correlation data sets in the 1990s, variance-covariance method has become the main approach to calculate the VaR[9]. More recent studies by Berggren and Folkelid suggest that asymmetrical models perform better than symmetrical models by comparing different VaR figures and Garch models[10]. Gou Hongjun and others are studying the risks of four types of CNY exchange rate asset portfolios: Euro, CNY, Japanese Yen and Hong Kong Dollar, finding that the VaR of the asset portfolio obtained by the GARCH-EVITCopula model is better[11].

In view of the above discussion, the theoretical research on futures-spot hedging mainly focused on the comparison of methods for determining the optimal hedging ratio. In the study of linear methods, the GARCH model is slightly more dominant over the OLS static model; with the introduction of the Copula model, the nonlinear method has gained wider recognition. There are also more measurement models used as the marginal distribution, so that the performance of futures and spot hedging is continuously optimized.

\subsection{The Main Contents}

The main contents of this article focus on constructing a future hedging portfolio to obtain the most stable return on assets. First, we introduces the purpose and significance of this article, related research and reviews worldwide, the main content, research methods and innovations. The second chapter presents the preliminaries of this paper. We describes the content of the Hedging Ratio under the Idea of Minimum Variance futures hedging, elaborates basic principles and operational mechanism of hedging. The third chapter introduces the data, indicators and statistical tests selected in this empirical analysis. The fourth chapter is the empirical analysis, which is the core of this paper. By using VaR to measure the risk level of crude oil spot price with and without hedging, it is demonstrated that crude oil futures can play a certain role in risk management and control. The fifth chapter proposes some feasible suggestions for corporate and individual investors based on the analysis in this work, and the entire work is summarized.

\subsection{Innovation}

The real data of WTI oil price were analyzed with time efficiency. The comparative analysis of VaR before and after hedging was used to obtain the effectiveness of the strategy with credibility.

This article uses commodity futures to analyze the hedging effect of systematical risks in the spot market and provides pragmatic countermeasures and suggestions to the majority of small and medium investors.

\section{METHOD}

\subsection{The Hedging Ratio under the Idea of Minimum Variance}

The purpose of the minimum variance hedging model is to minimize the risk of the investors, that is, to construct the current investment portfolio with yield fluctuation as little as possible, so the optimal hedging strategy should minimize the change of the portfolio position during the hedging period. According to the different direction of the transaction, there are two types of futures hedging: long hedging and short hedging. The investor needs to buy the spot asset at a certain time in the future in the long hedging. In order to avoid the increase of transaction costs as the market price rises, the investor buys the futures contract and at the end of the hedging he sells it, so that the price difference in the futures market can make up for the price change in the spot market. Short hedging is when the investor sells a spot asset at some point in the future, in order to protect against a decline in the price, the investor sells a futures contract in the futures market, and buys a futures contract to close out the position at the end of the hedging.

Ederington add the connotation of MVH (minimum variance hedge)by adding Basis Risk into Portfolio Risk[5]. This article discussed minimum variance hedge ratio theory in hedge practice. The hedging ratio refers to the ratio of the position of the hedging asset (such as forward and futures) to the position of the asset protected by the hedging.

Suppose $\lambda_{1}$ is the spot quantity bought in the spot market, $\lambda_{2}$ is the futures quantity sold in the futures market, at time t $S_{t}$ is spot prices and $F_{t}$ is futures prices, then: 


$$
R_{s}=\frac{\Delta S_{t}}{S_{t}}, R_{f}=\frac{\Delta F_{t}}{F_{t}}, \Delta S_{t}=S_{t}-S_{t-1}, \Delta F_{t}=F_{t}-F_{t-1}
$$
in which $R_{s}$ and $R_{f}$ are spot and futures yield respectively, and portfolio yield $R_{h}$ is:

$$
R_{h}=\frac{\lambda_{1} \Delta S_{t}-\lambda_{2} \Delta F_{t}}{\lambda_{1} S_{t}}=R_{\mathrm{s}}-h R_{f}
$$

in which $\mathrm{h}$ is the hedging ratio, the variance of $R_{h}$ is:

$$
\operatorname{Var} R_{h}=\operatorname{Var} R_{S}+h^{2} \operatorname{Var} R_{f}-2 h \operatorname{Cov}\left(R_{S}, R_{j}\right)
$$

The first derivative of $\mathrm{h}$ is taken, and the following equation can be concluded:

$$
2 h \operatorname{Var} R_{f}-2 \operatorname{Cov}\left(R_{s}, R_{f}\right)=0
$$

which can be further elaborated as:

$$
h=\frac{\operatorname{Cov}\left(R_{s}, R_{f}\right)}{\operatorname{Var} R_{f}}=\rho \frac{\sigma_{s}}{\sigma_{f}}
$$

in which $\rho$ is the correlation coefficient of $R_{s}$ and $R_{f}$, $\sigma_{s}$ and $\sigma_{f}$ are the standard deviations of $R_{s}$ and $R_{f}$, respectively.

The advantage of this model is that only the variance and linear correlation coefficient are calculated according to the historical data, and the hedging ratio can be solved by minimizing the variance of spot and futures portfolios. The disadvantage is that when the futures price and spot price change greatly, the linear correlation coefficient between futures and spot price will lead to inaccurate calculation results, because the linear correlation coefficient only reflects the correlation under the scenario of linear relationship[12].

\section{2. linear 'GARCH'model}

In addition, we also discussed the 'linear GARCH'model[13], which is used to analyze the financial data and obtain the optimal hedging ratio. The GARCH $(1,1)$ contains mean equation and conditional variance equation.

\subsection{Overview of Hedging Principle}

In the futures market, investors are worried about the future price increase of the spot market, so investor can bet them long. In this way, even if the spot price does rise, the profits made in the futures market can hedge the risk. Under usual circumstances, there is a common trend with prices in the spot and futures markets, rising and falling at the same time because both markets are affected by the same supply and demand. But because investors take opposite positions in the two markets, profit and loss cancel each other out.

\subsection{Role of Hedging}

When the enterprise signs a spot supply contract with the client to ensure future good delivery, in order to avoid the rising of raw material price in the future, the enterprise can buy the raw material in the futures market to lock in profits. When the enterprise signs a spot supply contract with the client to ensure future good delivery, in order to avoid the decline of raw material price in the future, the enterprise can sell the raw material in the futures market to lock in profits. When the enterprise needs financing support, it can obtain a higher financing ratio from banks or related institutions by pledging futures warehouse receipts. By hedging, the enterprise can send a signal to the potential investors that the enterprise is doing well and greatly enhance the confidence of creditors[14].

\subsection{Risk of Hedging}

Proper use of financial derivatives for hedging can effectively reduce the business risks caused by price fluctuations, but due to the inherent characteristics of hedging, even if the correct use of financial derivatives, the enterprise may suffer losses, and this is called endogenous risks, including: basis risk, credit risk, liquidity risk and risk caused by external events.

\subsubsection{Endogenous Risks}

\subsubsection{Basis Risk}

The basis is the difference between the spot price and the futures price. Basis risk refers to the adverse effects of changes in basis. The basis risk mainly comes from: the basis between spot and futures and the changes in the hedging; the futures price is equal to the spot price plus the cost of carry, which also changes the basis; when the spot assets and hedging assets do not match, the price trend of the two may not be consistent, if the gap is too large, it will bring greater basis risk; trading markets are not fully efficient and prices do not reflect all the information contained in a timely manner[15].

\subsubsection{Credit Risk}

In floor trading market, traders trade with the exchanges, so there is generally no credit risk. But in the OTC market, the two sides of the traders do not rely on the exchange to trade directly, there is a large credit risk. A default situation is highly possible when a counterparty loses money.

\subsubsection{Liquidity Risk}

Liquidity risk refers to the additional risk caused by the difficulty to establish or close the position in time. Trading in exchange is conducted via standardized contracts, timely trading can be realized within the exchange with strong liquidity; on the contrary, the liquidity of the OTC market is very poor due to nonstandardized contracts, and it is difficult to find suitable counterparties, so the liquidity risk is obvious. 


\subsubsection{Exogenous Risks}

Exogenous risk has nothing to do with hedging itself but is caused by the wrong use of financial derivatives by enterprises. Exogenous risk mainly includes operational risk, moral risk, institutional risk and speculative risk.

\section{6. $V a R$}

Artzner et al.[16] defined var in mathematics as follows:

$$
\mathrm{VaR}=-\inf \{\mathrm{y} \mid \operatorname{Pr}[\Pi \leqslant \mathrm{y}]>1-c\}
$$

$\Pi$ Is the future profit and loss of the asset portfolio, c is confidence level, $\inf \{y A\}$ is the infimum of the set of all $\mathrm{y}$ that make A hold. We uses historical simulation method and the delta-normal approach to calculate $\operatorname{VaR}[16]$.

\section{DATA COLLECTION AND STATISTICAL TESTS}

\subsection{Data Preparation}

The object analyzed is WTI crude oil, futures and spot prices were obtained from Wind. The time period covered in the analysis was from June 19th, 2000 to January 30th, 2021.

Moreover, logarithmic process was applied to measure the return rate. The logarithmic return can be expressed as:

$$
R=\ln P_{t}-\ln P_{t-1}
$$

Eviews 7.0 was used in this paper to conduct statistics analysis.

\subsection{Statistical Analysis}

\subsubsection{Descriptive Statistics}

Eviews was used to analyze the descriptive statistics of the data. The descriptive statistical analysis of the logarithmic yield of crude oil futures is shown in Table 1 and Table 2:

Table 1. Descriptive Statistical Analysis of Crude Oil Spot Yields

\begin{tabular}{|l|l|}
\hline Mean & -0.002406 \\
\hline Median & 0.000000 \\
\hline Maximum & 0.241655 \\
\hline Minimum & -0.456845 \\
\hline Std. Dev. & 0.117686 \\
\hline Skewness & -0.905751 \\
\hline Kurtosis & 6.036620 \\
\hline Jarque-Bera & 35.94497 \\
\hline Probability & 0.000000 \\
\hline
\end{tabular}

\begin{tabular}{|l|l|}
\hline Sum & -0.165985 \\
\hline Sum Sq. Dev. & 0.941805 \\
\hline Observations & 69 \\
\hline
\end{tabular}

Table 2. Descriptive Statistical Analysis of Crude Oil Futures

\begin{tabular}{|l|l|}
\hline Mean & -0.002406 \\
\hline Median & 0.000000 \\
\hline Maximum & 0.241655 \\
\hline Minimum & -0.456845 \\
\hline Std. Dev. & 0.117686 \\
\hline Skewness & -0.905751 \\
\hline Kurtosis & 6.036620 \\
\hline Jarque-Bera & 35.94497 \\
\hline Probability & 0.000000 \\
\hline Sum & -0.165985 \\
\hline Sum Sq. Dev. & 0.941805 \\
\hline Observations & 69 \\
\hline
\end{tabular}

It can be seen in Table 1 that the skewness of the crude oil spot yield series is -0.905751 , which means it is left-skewed; the Kurtosis is 6.033620 , which is greater than 3, showing peak characteristics; Jarque-Bera Statistics is 35.94497. However, Jarque-Bera Statistics of the normal distribution ( $95 \%$ confidence interval) is 5.991. Results indicate that it does not obey the normal distribution. In Table 2, the peak value of the return rate series is greater than 3, indicating that the price fluctuations of market futures consistently show excess kurtosis and sharp peak.

The result of normality test shows that, since the pvalue is about chance of committing a Type I error, it can be seen in the above table that the oil futures return sequence disobeys the normal distribution.

\subsubsection{Unit Root Test}

Eviews was used to perform unit root tests on the prices of crude oil spot and futures to determine if the time series is stationary. that is, to verify that the covariance and mean of the sequence are independent of time. Table 3 and Table 4 present the results.

Table 3. Unit Root Test Results of Crude Oil Spot Prices

\begin{tabular}{|c|l|l|l|}
\hline \multicolumn{2}{|c|}{} & t-Statistic & Prob. $^{*}$ \\
\hline \multicolumn{2}{|c|}{$\begin{array}{c}\text { Augmented Dickev-Fuller test } \\
\text { statistic }\end{array}$} & - & 0.2614 \\
\hline \multirow{2}{*}{$\begin{array}{c}\text { Test critical } \\
\text { values: }\end{array}$} & $1 \%$ level & - & - \\
& & 3.527045 & \\
\cline { 2 - 4 } & $5 \%$ level & - & \\
\cline { 2 - 4 } & $10 \%$ level & - & - \\
& & 2.503566 & \\
& & & \\
\hline
\end{tabular}


Table 4. Unit Root Test Results of Crude Oil Futures Prices

\begin{tabular}{|c|l|l|l|}
\hline \multicolumn{2}{|c|}{} & t-Statistic & Prob. $^{*}$ \\
\hline $\begin{array}{c}\text { Augmented Dickev-Fuller test } \\
\text { statistic }\end{array}$ & -2.60549 & 0.0968 \\
\hline \multirow{2}{*}{$\begin{array}{c}\text { Test critical } \\
\text { values: }\end{array}$} & $1 \%$ level & - & \\
\cline { 2 - 4 } & $5 \%$ level & - & \\
& & 2.528515 & \\
\cline { 2 - 4 } & $10 \%$ level & - & \\
& & 2.589562 & \\
\hline
\end{tabular}

The above results indicate that the $t$-Statistic of the unit root test of the crude oil spot price is -2.059822 , which is greater than the critical value -2.903566 , so variables are nonstationary.

The t-Statistic for the unit root test of crude oil futures prices is -2.0605490 , which is greater than the critical value -2.904198, which means both series are nonstationary. Subsequently, the first order difference process was used to solve the problem of nonstationary, and the results are shown in Table 5 and Table 6:

Table 5. Unit Root Test of Crude Oil Spot Prices after First Order Difference

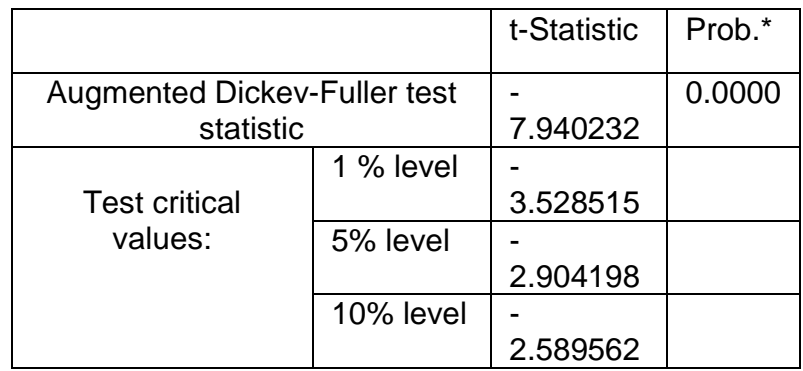

Table 6. Unit Root Test of Crude Oil Futures Prices After First Order Difference

\begin{tabular}{|c|l|l|l|}
\hline \multicolumn{2}{|c|}{} & t-Statistic & Prob. $^{*}$ \\
\hline $\begin{array}{c}\text { Augmented Dickev-Fuller test } \\
\text { statistic }\end{array}$ & - & 0.0000 \\
\hline \multirow{2}{*}{$\begin{array}{c}\text { Test critical } \\
\text { values: }\end{array}$} & $1 \%$ level & - & \\
\cline { 2 - 4 } & $5 \%$ level & - & \\
& & 2.530030 & \\
\cline { 2 - 4 } & $10 \%$ level & - & \\
& & 2.589907 & \\
\hline
\end{tabular}

In the above results, the t-Statistic of the crude oil spot price is -7.940232 , which is less than the critical value 2.904198 , so this series is stationary. The t-Statistic of crude oil futures prices is -6.612376 , which is less than the critical value -2.904948 , so this series is stationary. As a result, the variances can be fitted with measurement models.

\subsubsection{Co-integration Test}

It is necessary to employ co-integration tests into different time series to verify that a linear combination could have linear relations. Firstly, the co-integration relationship between the yield series of crude oil futures and spot was judged intuitively:

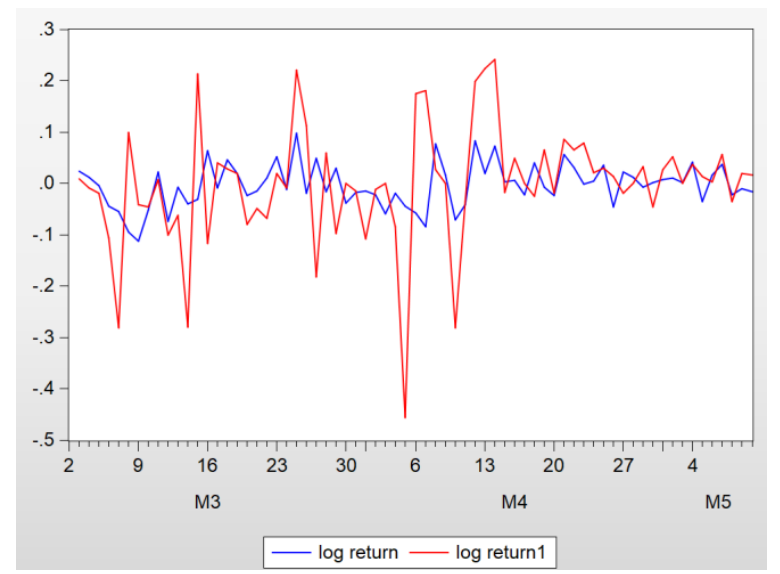

Figure 1 Crude Oil Futures and Spot Yield Volatility Chart

Figure1 is the volatility chart of the yield series of crude oil futures and spot. Both polylines fluctuate up and down, indicating that two sequences are non-stationary, which can be regarded as random walk, but the trends of the two sequences are similar. Then, residual-based procedure was proposed in the context of testing for unit root.

Table 7. Result of Residual Unit Root Test

\begin{tabular}{|c|c|c|c|}
\hline & & t-Statistic & Prob. ${ }^{*}$ \\
\hline $\begin{array}{r}\text { Augmented Di } \\
\text { stat }\end{array}$ & Fuller test & $\begin{array}{l} \\
9.184927\end{array}$ & 0.0000 \\
\hline Test critical & $1 \%$ level & $\begin{array}{l}-530030 \\
3.53\end{array}$ & \\
\hline values: & $5 \%$ level & $\begin{array}{l}- \\
2.904848\end{array}$ & \\
\hline & $10 \%$ level & $\begin{array}{l}- \\
2.589907\end{array}$ & \\
\hline
\end{tabular}

According to Table7, the t-Statistic is -9.184927 , which is less than the critical value -2.904848 , so the residual sequence is stationary. Therefore, there is a cointegration relationship between spot price and future price.

\subsubsection{Granger Causality Test}

Granger causality test was carried out on crude oil futures and spot prices to verify the possible causal relationship between the futures and spot prices, and the results are shown in the Table 8:

Table 8. Granger Causality Test Results

$\begin{array}{lll}\text { Null Hypothesis: } & \text { Obs F-Statistic Prob. } \\ \text { PRICE does not Granger Cause PRICE1 68 } & 3.09509 & 0.0522 \\ \text { PRICE1 does not Granger Cause PRICE } & 3.89482 & 0.0254\end{array}$

As can be seen from the Table8, in the first row, the probability of the null hypothesis error is $5.22 \%$, which 
is higher than the confidence level of $5 \%$, indicating that there is no Granger causality between futures and spot price. In the second row, the probability of the null hypothesis error is $2.54 \%$, which is less than $5 \%$, indicating that there is granger causality between the spot and futures price. In other words, the crude oil futures price has a relatively obvious response to the information about the spot price, while the spot price has no obvious response to the information about the futures.

\section{HEDGING EFFECT ANALYSIS OF CRUDE OIL FUTURES BASED ON VAR AND GARCH MODELS}

\subsection{Calculation of VaR (Value at Risk) for Crude Oil Spot Daily Yield}

The historical simulation method and "delta-normal" method were used to calculate the VaR of crude oil spot daily yield, and $\mathrm{R}$ language was leveraged to conduct programming, the results are that: the VaR of the crude oil spot daily return rate calculated by the historical simulation method is 235 , and the VaR calculated by the "dalta-normal" method is 192.405044 .

\subsection{Calculation of the Optimal Hedging Ratio}

The least square method and GARCH model are the linear methods commonly applied to determine the optimal hedging ratio. Since the results obtained from the least square method is often associated with the ARCH effect on the residual, which greatly reduces model accuracy, in this paper, the GARCH model was leveraged to calculate the optimal hedging. Regression was conducted on the yield series of crude oil spot and futures by leveraging GARCH $(1,1)$ model, and the results are shown in Table 9:

Table 9. Regression Results of GARCH $(1,1)$

\begin{tabular}{|c|c|c|c|c|}
\hline Variable & Coefficien & tStd. Error & -Statistic & Prob. \\
\hline$\underset{\text { LOG_RETURI }}{\mathrm{C}}$ & $\begin{array}{r}0.016773 \\
\text { V } 1.068581\end{array}$ & $\begin{array}{l}0.009977 \\
0.245703\end{array}$ & $\begin{array}{l}1.681153 \\
4.349068\end{array}$ & $\begin{array}{l}0.0927 \\
0.0000\end{array}$ \\
\hline \multicolumn{5}{|c|}{ Variance Equation } \\
\hline $\operatorname{RESID(-1)^{\wedge }{}^{C}}$ & $\begin{array}{l}0.002775 \\
1.672554\end{array}$ & $\begin{array}{l}0.001388 \\
0.478963\end{array}$ & $\begin{array}{c}1.998776 \\
3.492028\end{array}$ & $\begin{array}{l}0.0456 \\
0.0005\end{array}$ \\
\hline GARCH(-1) & 0.018480 & 0.089382 & 0.206750 & 0.8362 \\
\hline
\end{tabular}

Based on which the model equation can be listed as follows:

The mean value equation is:

$$
\begin{gathered}
R_{1}=1.068581 R_{2}+\varepsilon_{t} \\
\text { s.e. }=(0.245703) \\
z=(4.349068)
\end{gathered}
$$

The conditional variance equation is:

$$
\begin{gathered}
h_{t}=0.002775+1.672554 \varepsilon_{t-1}{ }^{2}+0.018480 h_{t-1} \\
\text { s.e. }=(0.001388)(0.478963)(0.089382) \\
z=(1.998776)(3.492028)(0.206750)
\end{gathered}
$$

In the equation, $R^{2}=0.865715$, log likelihood $=$ 634.2891, $\mathrm{AIC}=-7.3654213, \mathrm{SC}=-7.268114$. In the above equation, $R_{1}$ represents the crude oil spot yield, $R_{2}$ represents the futures yield, and the coefficient before $R_{2}$ is 1.068581 , which is the optimal hedging ratio. According to the above results, conclusions can be made that the regression results of $\mathrm{GARCH}(1,1)$ are significant and meet the requirements of SIC and AIC criteria. Then $\mathrm{ARCH}$ LM test was carried out to verify whether heteroscedasticity existed. The results are shown in Table 10 :

Table 10. ARCH (3) test results of residual term sequence of GARCH $(1,1)$ model

\begin{tabular}{|l|l|l|l|}
\hline F-statistic & 0.232763 & Prob. F(3,62) & 0.8732 \\
\hline $\begin{array}{l}\text { Obs }{ }^{*} \mathrm{R} \text { - } \\
\text { squared }\end{array}$ & 0.735062 & $\begin{array}{l}\text { Prob. Chi- } \\
\text { Square(3) }\end{array}$ & 0.8649 \\
\hline
\end{tabular}

As can be seen from Table 10, the conjoint probability is 0.8732 , which is much larger than 0 , in other words, there is no $\mathrm{ARCH}$ effect in the residual term sequence obtained by GARCH $(1,1)$ model regression, and the optimal hedging ratio calculated by this model is viable.

\subsection{Analysis of Basis Yield Data}

According to the optimal hedging ratio calculated above, structural combination of crude oil futures and spot assets was carried out, then the basis yield after hedging was calculated, and descriptive statistics and unit root test were carried out. The results are shown in Table 11:

Table 11. Descriptive Statistics of Basis Yield

$\begin{array}{ll} & \text { RETURN } \\ \text { Mean } & 0.001481 \\ \text { Median } & 0.002712 \\ \text { Maximum } & 0.270581 \\ \text { Minimum } & -0.409919 \\ \text { Std. Dev. } & 0.112350 \\ \text { Skewness } & -0.555220 \\ \text { Kurtosis } & 5.397063 \\ \text { Jarque-Bera } & 20.06459 \\ \text { Probability } & 0.000044 \\ \text { Sum } & 0.102185 \\ \text { Sum Sq. Dev. } & 0.858331 \\ \text { Observations } & 69\end{array}$

It can be seen from the Table 11, the skewness of the basis yield is -0.555220 , which is left-biased. Kurtosis is 5.397063, showing a sharp peak characteristic, so it is a left-skewed sharp peak distribution; JB normal statistic is 
20.06459, which is greater than the value of normal distribution at $95 \%$ confidence level, indicating that it does not obey normal distribution.

Table 12. Unit Root Test Results of Basis Yield

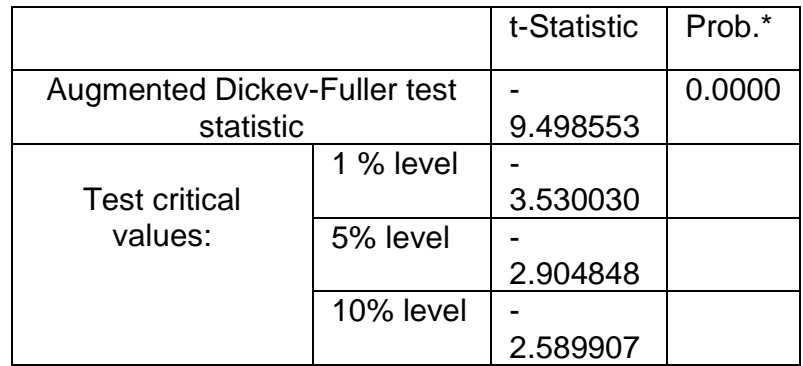

It can be seen from Table 12, the unit root test results that the T statistic is -9.498553 , which is smaller than the critical value -2.904848 , in other words, there is no unit root in the series and it is a stationary series, and the volatility can be calculated.

\subsection{Calculation of VaR of Hedging Portfolio}

According to the historical simulation method and "delta-normal" method, the VaR of daily yield of crude oil hedging portfolio can be calculated with $\mathrm{R}$ language, and the results is shown in Table 13:

Table 13. VaR Calculation Results of Daily Yield of Hedging Portfolio

\begin{tabular}{|l|l|}
\hline VaR1 & 184.799306224967 \\
\hline VaR2 & 216.1604 \\
\hline
\end{tabular}

Therefore, in Table13, according to the historical simulation method, the VaR of daily yield of crude oil hedging portfolio is 216.1604 , which is less than the prehedging VaR of 235, and the VaR calculated by "delta Normal" method is 184.799306 , which is less than the pre-hedging VaR of 192.405044. Therefore, it can be concluded that under two different calculation methods of $\mathrm{VaR}$, the hedging portfolio reduces the VaR of spot crude oil, in other words, it reduces the systematic risk of investors' asset portfolio to a certain extent.

\section{CONCLUSION}

\subsection{Suggestions to Investors}

It has only been two years since crude oil futures contract started trading in China, and most investors still have only a rudimentary understanding of it. The oil industry has been hit hard by the global economic downturn, and many investors have lost money in oilrelated investments. Some investors holding crude oil related products in their personal account in Bank of China lost as high as 9.2 million yuan[18]. To better prepare for such black swan events in the future, both corporate and individual investors should proactively learn hedging strategies including the use of oil futures hedging. Specifically, investors should promptly pay attention to the systematical risks of the market and actively understand the potential crisis in the investment field. When using crude oil futures hedging to reduce investment risk, it is necessary to understand the relevance of spot and futures products, and to understand the proportion of systematical risk in spot market investments, to choose the right futures for hedging, to determine the proper execution time of hedging strategy, to adjust positions in a timely manner, so to achieve the optimal effect of investment risk control. Hedging is not always a perfect way to manage risk, because the optimal hedging ratio is almost always calculated based on historical data. However, no one can accurately predict price in the future, and the market is full of volatility and uncertainty. Only by strengthening the professional knowledge of financial investment and enhancing the awareness of risk management, can stable investment returns be obtained and risk control under the impact of economic downturn be ensured.

\subsection{Summary}

By analyzing the possibility of hedging, this paper finds out the optimal hedging ratio and verifies its effectiveness: 1. Through researching on the systematical risk of the US crude oil market, it is found that the WTI crude oil market fluctuates greatly; there is a high correlation between crude oil futures and spot, and the use of crude oil futures for hedging has certain positive effect on risk management. 2. The statistical analysis of WTI spot and futures yield shows that WTI spot yield does not follow normal distribution, while the yield of crude oil futures is normally distributed. The two sequences are stationary and have co-integration relationship. 3. The series of the basis yield of the hedging portfolio is a stationary series. 4. In this analysis, VaR model and GARCH model are used to compare the risk level of crude oil portfolio yield before and after hedging. It is found that the VaR of portfolio yield after applying the optimal hedging ratio is less than the VaR before hedging, which indicates that it is of practical significance to use futures hedging to control the risks of enterprises and individual investors. The shortcomings of this paper are as follows: 1 . This paper studies the price fluctuation risk control of WTI spot and futures but does not provide a practical plan in the actual investment process. Based on the core idea of this analysis, investors can realize hedging and risk management through portfolio construction. 2. It is found in the empirical study that the reduction of VaR before and after hedging is not obvious. Moreover, due to the characteristics of the current futures market, there is no trading in holidays, so the selected data are not continuous, which makes it impossible to take full advantages of the GARCH model. In practice, there should be a better hedging ratio. 3.The expiration effect of futures is not considered in this paper. In the practical application of hedging, the futures price will fluctuate sharply as the expiration date approaches. 
Taking this into account, the hedging performance will be more obvious.

\section{REFERENCES}

[1] BBC (2020) US oil prices turn negative as demand dries up. https://www.bbc.com/news/business52350082

[2] Keynes, J.M. (1930) A Treatise on Money, Vol. 2. Macmillan, London.

[3] Hicks, J.R. (1946) Value and Capital, 2nd edn. Oxford University Press, London.

[4] Working, H. (1953) Futures trading and hedging. The American Economic Review, 43(3): 314-343.

[5] Ederington, L. H. (1979) The hedging performance of the new futures markets. The journal of finance, 34(1): 157-170.

[6] Herbst, A. F., Kare, D. D., \& Caples, S. C. (1989) Hedging effectiveness and minimum risk hedge ratios in the presence of autocorrelation: Foreign currency futures. Journal of Futures Markets, 9(3): 185-197.

[7] Baillie, R. T., \& Myers, R. J. (1991) Bivariate GARCH estimation of the optimal commodity futures hedge. Journal of Applied Econometrics, 6(2): 109-124.

[8] Peng, H \& Ye, Y. (2007). Optimal hedging Ratio estimation and comparison of Chinese Copper Futures. Wuhan University Journal (Philosophy \& Social Sciences), (06): 863-868.

[9] Philippe Jorion. (2001) Value at Risk, 2nd Edition. McGraw-Hill, New York.

[10] Berggren, E., \& Folkelid, F. (2015) Which GARCH model is best for Value-at-Risk?.p.27.

[11] GOU,H., CHEN, X., \&HUA, Y. (2015) Research on foreign exchange portfolio risk measurement based on GARCH-EVT-Copula model. Journal of Industrial Engineering and Engineering Management, 29(1):183-193.

[12] Lence, S. H. (1995) The economic value of minimum-variance hedges. American Journal of Agricultural Economics, 77(2): 353-364.

[13] Bollerslev, T. (1986) Generalized autoregressive conditional heteroskedasticity. Journal of econometrics, 31(3): 307-327.

[14] Clemen, G. (1997) The concept of hedging: Origins, approaches and definitions. In: Raija Markkanen, and Hartmut Schröder (Eds.), Hedging and Discourse Approaches to the Analysis of a
Pragmatic Phenomenon in Academic Texts. De Gruyter, Berlin. pp. 235-248.

[15] Hull, J. C. (2003) Options futures and other derivatives. Pearson Education India, Delhi.

[16] Artzner, P., Delbaen, F., Eber, J. M., \& Heath, D. (1999) Coherent measures of risk. Mathematical finance, 9(3): 203-228.

[17] Linsmeier, T. J., \& Pearson, N. D. (2000) Value at risk. Financial Analysts Journal, 56(2): 47-67.

[18] NIKKEI Asia (2020) Four things to know about the 'paper crude' futures collapse. https://asia.nikkei.com/Spotlight/Caixin/Fourthings-to-know-about-the-paper-crude-futurescollapse 